\title{
Development of a Storage Getter Test for Cu Contaminations in Silicon Wafers Based on ToF-SIMS Measurements
}

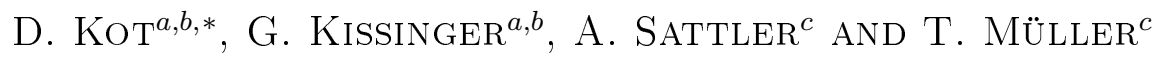 \\ ${ }^{a}$ IHP, Im Technologiepark 25, 15236 Frankfurt (Oder), Germany \\ ${ }^{b}$ BTU Cottbus, Joint Lab IHP/BTU, Konrad-Wachsmann-Allee 1, D-03046 Cottbus, Germany \\ ${ }^{c}$ Siltronic AG, Hanns-Seidel-Platz 4, 81737 München, Germany
}

\begin{abstract}
This work presents development and results of a storage getter test based on the measurement of the metal concentration by time-of-flight secondary ion mass spectroscopy applied for a low Cu contamination level. It was found that $\mathrm{Cu}$ atoms introduced into the as-grown sample by a drive-in anneal at high temperature diffuse out from the bulk to the surface within 7 days of storage at room temperature. Annealing steps at low temperature should decrease the time which $\mathrm{Cu}$ needs for the outdiffusion to the surface. However, the $\mathrm{Cu}$ atoms in samples subjected to outdiffusion annealing at $250{ }^{\circ} \mathrm{C}$ or $400^{\circ} \mathrm{C}$ precipitated in the bulk. The investigation of the getter efficiency by the storage test in silicon samples containing oxygen precipitates has shown that in order to achieve a getter efficiency above $90 \%$, the density of bulk microdefects should be higher than $6 \times 10^{9} \mathrm{~cm}^{-3}$.
\end{abstract}

DOI: $10.12693 /$ APhysPolA.125.965

PACS:

\section{Introduction}

$\mathrm{Cu}$ atoms are one of the most harmful impurities for ultra-large scale integration devices. Due to the high solubility and diffusivity of $\mathrm{Cu}$ in silicon, $\mathrm{Cu}$ atoms can easily contaminate silicon wafers even at room temperature. One method which is used to remove $\mathrm{Cu}$ impurities from the device region is internal gettering (IG) which is based on oxygen precipitates generated in the bulk of silicon wafers. In order to determine the getter efficiency of oxygen precipitates, different getter tests can be used. The haze test is a fast and easy to perform method, and the equipment is of low cost [1]. Due to these advantages, this method is often used to determine the getter efficiency $[2,3]$. However, the haze test uses a high level of contamination. Since the fabrication of microelectronic devices is a very pure process and the level of possible contamination is relatively low, the results of the haze test are rather inappropriate. It has been already demonstrated that the getter efficiency of oxygen precipitates for $\mathrm{Cu}$ strongly depends on the initial contamination level [4]. Therefore, many getter tests with low initial contamination level were developed. Most of them are based on contamination by spin coating. The concentration of metals is measured by ICP-MS or GF-AA after dissolution of the silicon layers containing metal atoms by chemical etching [5-7]. Although, the sensitivity of these getter tests is very high, they require whole wafers for the tests and just deliver an average getter efficiency for the whole wafer. In this work, a getter test based on the measurement of the surface concentration of $\mathrm{Cu}$ by time-of-flight secondary ion mass spectroscopy (ToF-SIMS)

*corresponding author; e-mail: kot@ihp-microelectronics.com was developed. The advantage of this test is the possibility to investigate several small samples of about $1 \mathrm{~cm}^{2}$ from certain locations on a wafer simultaneously and the measurement time is very short.

So far, the SIMS method was mainly used for the investigation of the getter efficiency in implanted samples. The aim of such investigations was to measure the concentration depth profile and to observe the site of metal aggregation in the implanted projected range $[8,9]$. The application of ToF-SIMS for the investigation of the metal concentration on the surface is much more difficult because of undesired surface effects which can influence the value of the measured concentration.

This work describes the development of a ToF-SIMS getter test, the problems which are associated with the measurement of the surface concentration and its limitations. Finally, the getter efficiency of oxygen precipitates is investigated by a 7 day storage getter test.

\section{Experimental}

The samples used for the investigations were mainly cut out from two types of wafers. One part of samples was cut out from $B$-doped (100) Czochralski (CZ) silicon wafers $200 \mathrm{~mm}$ in diameter with resistivity of about $10 \Omega \mathrm{cm}$. The concentration of interstitial oxygen according to DIN $50438 / 1$ was $6.5 \times 10^{17} \mathrm{~cm}^{-3}$. This type of samples will be named in the following "low Oi". The second type of wafers used was $B$-doped (100) CZ-Si $150 \mathrm{~mm}$ in diameter with a resistivity of about $50 \Omega \mathrm{cm}$. The concentration of interstitial oxygen according to DIN $50438 / 1$ was $8.5 \times 10^{17} \mathrm{~cm}^{-3}$. This type of wafer will be called "high Oi". Both wafer types were polished on the front side and etched on the back side. For the development of the ToF-SIMS 7 day storage getter test, four types of samples were used. The first sample was cut 
out from a low Oi wafer. This sample was pre-treated by rapid thermal annealing (RTA) at $1250^{\circ} \mathrm{C}$ for $30 \mathrm{~s}$ and annealed at $800^{\circ} \mathrm{C}$ for $32 \mathrm{~h}$ in $\mathrm{N}_{2}$. The second sample was cut out from a high $\mathrm{Oi}$ wafer. The third sample was cut out from a float zone (FZ) silicon wafer and the fourth from an $n$-type $\mathrm{CZ}$ silicon wafer.

For the investigation of the getter efficiency in the samples contaminated with low concentration of $\mathrm{Cu}$, both the low and the high Oi wafers were used. The samples were pre-treated by RTA at $1175{ }^{\circ} \mathrm{C}, 1200^{\circ} \mathrm{C}, 1225^{\circ} \mathrm{C}$, or $1250{ }^{\circ} \mathrm{C}$ for $30 \mathrm{~s}$ and annealed at $800^{\circ} \mathrm{C}$ for $1 \mathrm{~h}, 2 \mathrm{~h}, 4 \mathrm{~h}$, $8 \mathrm{~h}, 16 \mathrm{~h}$, or $32 \mathrm{~h}$ in $\mathrm{N}_{2}$. After that, the samples of the low $\mathrm{Oi}$ and the high Oi wafers were contaminated with $\mathrm{Cu}$ in the range of $1.0 \times 10^{13} \mathrm{~cm}^{-2}$ and $5.0 \times 10^{12} \mathrm{~cm}^{-2}$, respectively, and subjected to the ToF-SIMS 7 day storage getter test.

In order to investigate the influence of large oxygen precipitates on the bulk micro defects (BMD) density some samples were subjected to an additional growth anneal and then investigated by the ToF-SIMS 7 day storage getter test.

\section{Results and discussion}

\subsection{Development of the ToF-SIMS getter test}

\subsubsection{Contamination procedure}

The first step of the getter test is the contamination of the silicon samples with a well-defined concentration of $\mathrm{Cu}$ and the confirmation of this concentration by an analyzing technique like ToF-SIMS. In this getter test, pieces of $\mathrm{Si}$ wafers with an area of $1 \mathrm{~cm} \times 1.3 \mathrm{~cm}$ were contaminated by dipping them in the contamination solution for $5 \mathrm{~min}$. In order to contaminate the surface with $1 \times 10^{13} \mathrm{~cm}^{-2}$ of $\mathrm{Cu}$ atoms, $70 \mu \mathrm{l}$ of $\mathrm{Cu}$ standard solution $(\mathrm{Cu} 1000 \mathrm{ppm})$ were mixed with $1 \mathrm{l}$ of $\mathrm{H}_{2} \mathrm{O}$. The pre-treatment of the sample surface plays a very important role for the measurement of the $\mathrm{Cu}$ concentration by ToF-SIMS. The measurement of the $\mathrm{Cu}$ concentration on the silicon surface is very sensitive to a native oxide therefore it is important to dip the sample in an HF solution before contamination. The relative sensitivity factor ( $\mathrm{RSF}$ ) of $\mathrm{Cu}$ which is used to calibrate the concentration measured is different for different materials [10]. This means that the amount of ejected ions can be different for silicon surfaces with oxide and without oxide layer.

Figure 1 shows the results of three samples contaminated with $\mathrm{Cu}$ by dipping the samples in the same $\mathrm{Cu}$ contamination solution. The first sample was annealed in oxygen atmosphere at $1000{ }^{\circ} \mathrm{C}$ to generate an oxide layer. The second sample was first dipped in an HF (5\%) solution for $10 \mathrm{~min}$ and then subjected to a hydrophilization treatment in a $\mathrm{NH}_{4} \mathrm{OH}: \mathrm{H}_{2} \mathrm{O}_{2}: \mathrm{H}_{2} \mathrm{O}$ (1:1:5) solution for $5 \mathrm{~min}$. The third sample was hydrophobized in an HF $(50 \%)$ solution for $10 \mathrm{~min}$. The concentrations determined by ToF-SIMS differ by orders of magnitude as demonstrated in Fig. 1. In the sample with an oxide, the very low concentration of $\mathrm{Cu}$ is caused by the matrix effect. This means that the RSF factor of $\mathrm{Cu}$ in silicon is no more valid in this kind of sample. In the sample subjected to a hydrophilization, some matrix effect can also take place therefore the concentration is smaller than in the third hydrophobized sample where the concentration measurement is reliable.

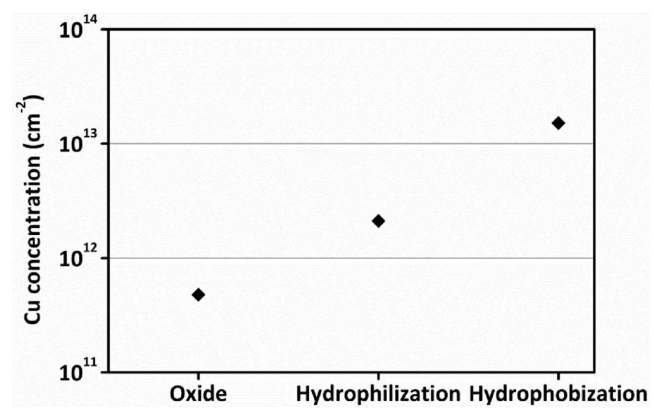

Fig. 1. Cu concentration measured on three differently pre-treated samples contaminated with $1 \times 10^{13} \mathrm{~cm}^{-2}$ of $\mathrm{Cu}$ atoms.

In many getter tests, the contamination is based on hydrophilization solutions which can be helpful in the homogeneous distribution of metals on the silicon surface especially for spin-on contamination [4]. However, as it was just demonstrated the hydrophilization pre-treatment can be of negative influence on the concentration measurement by ToF-SIMS.

An initial $\mathrm{Cu}$ concentration of $1 \times 10^{12} \mathrm{~cm}^{-2}$ can be obtained if $35 \mu \mathrm{l}$ of $\mathrm{Cu}$ standard solution mixed with $1 \mathrm{l}$ of $\mathrm{H}_{2} \mathrm{O}$ is twice diluted in $\mathrm{H}_{2} \mathrm{O}$ with a ratio of $0.1: 0.9$. The detection limit of the measurement of the $\mathrm{Cu}$ concentration on the silicon surface by this detection technique was about $1 \times 10^{10} \mathrm{~cm}^{-2}$.

\subsubsection{Drive-in anneal and storage}

After contamination, the samples were annealed at $1000{ }^{\circ} \mathrm{C}$ for $10 \mathrm{~min}$ in $\mathrm{N}_{2}$ in order to in-diffuse the $\mathrm{Cu}$ into the Si bulk. As the result of this drive-in anneal, the concentration of $\mathrm{Cu}$ on the surface of the sample decreases and the $\mathrm{Cu}$ getter efficiency was found to be above $90 \%$ in any kind of sample. It is impossible to measure a useful getter efficiency at this point in time, because after 7 days of storage at RT most of the ungettered $\mathrm{Cu}$ diffuses out of the bulk and returns to the surface of the sample. A similar effect was observed by [5]. If most of the $\mathrm{Cu}$ is gettered by defects the getter efficiency remains above $90 \%$ even after 1 month. In this case $\mathrm{Cu}$ is permanently trapped at getter sites. The process flow of the final ToF-SIMS 7 day storage getter test respecting all the results mentioned above is schematically shown in Fig. 2.

\subsubsection{Drive-out}

In order to accelerate the outdiffusion of ungettered $\mathrm{Cu}$ from the $\mathrm{Si}$ bulk and to make the getter test faster, an annealing step at temperatures higher than RT can be applied as reported by [5]. Oxide layers at the samples, exceeding $3 \mathrm{~nm}$ must be removed before outdiffusion because otherwise $\mathrm{Cu}$ will not diffuse out $[5,11]$. One 


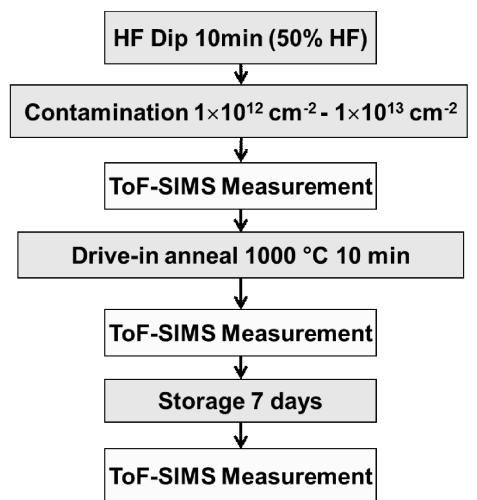

Fig. 2. Process flow of the ToF-SIMS 7 day storage getter test.

hour of annealing at $400{ }^{\circ} \mathrm{C}$ should be long enough to remove more than $90 \%$ of the $\mathrm{Cu}$ from $p$-type wafers [5]. However, the results obtained in this work are opposite as shown in Fig. 3. The getter efficiencies of as-grown samples ( $p$-type $\mathrm{CZ}, \mathrm{FZ}$, and $n$-type $\mathrm{CZ}$ ) subjected to a 7 day storage test are much lower than in the similar samples subjected to a drive-out anneal at $400{ }^{\circ} \mathrm{C}$ and $250^{\circ} \mathrm{C}$ for $1 \mathrm{~h}$. Even after 7 days, $\mathrm{Cu}$ atoms did not diffuse out of the samples subjected to the drive-out step. This means that the $\mathrm{Cu}$ remains in the bulk of the samples subjected to a drive-out anneal while in the samples subjected to a 7 seven day storage test a large part of the $\mathrm{Cu}$ diffuses out of the bulk. The sample indicated by $\mathrm{R}$ is a referential sample which contains oxygen precipitates and therefore exhibits a high getter efficiency.

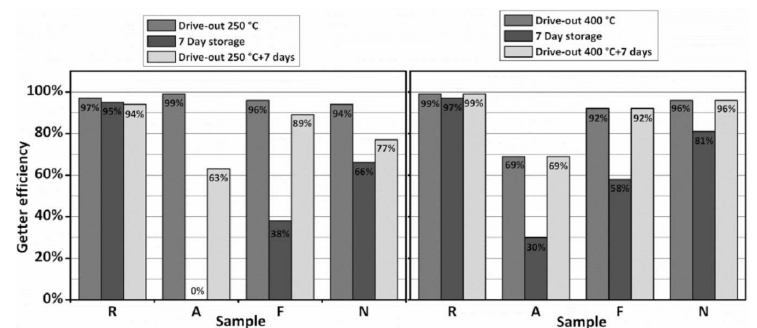

Fig. 3. Comparison of the results from a $250{ }^{\circ} \mathrm{C}$ or $400{ }^{\circ} \mathrm{C}$ drive-out tests and from a 7 day storage test. The initial $\mathrm{Cu}$ concentration was $\approx 1 \times 10^{12} \mathrm{~cm}^{-2}$. $\mathrm{R}-$ CZ samples with high BMD density, A - CZ as-grown $p$-type, $\mathrm{F}-\mathrm{FZ} p$-type, $\mathrm{N}-\mathrm{CZ}$ as-grown $n$-type.

The reason why $\mathrm{Cu}$ does not diffuse out of the Si bulk is illustrated in Fig. 4 where the images of preferentially etched as-grown samples are shown after dive-out annealing. On all the samples subjected to a drive-out anneal, characteristic etch pits of $\mathrm{Cu}$ precipitates were detected no matter if the initial concentration of $\mathrm{Cu}$ was $1 \times 10^{12} \mathrm{~cm}^{-2}$ or $1 \times 10^{13} \mathrm{~cm}^{-2}$. In case of the sample subjected to 7 day storage test, no etch pits were found. These results mean that the drive-out anneals cannot be used to accelerate the outdiffusion of $\mathrm{Cu}$ because the $\mathrm{Cu}$

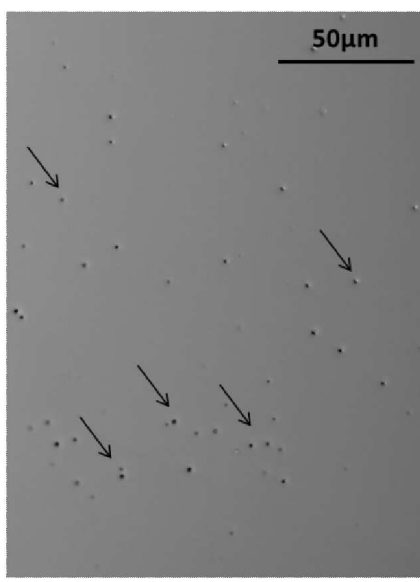

after $400^{\circ} \mathrm{C}$ drive-out Cu $1 \times 10^{13} \mathrm{~cm}^{-2}$

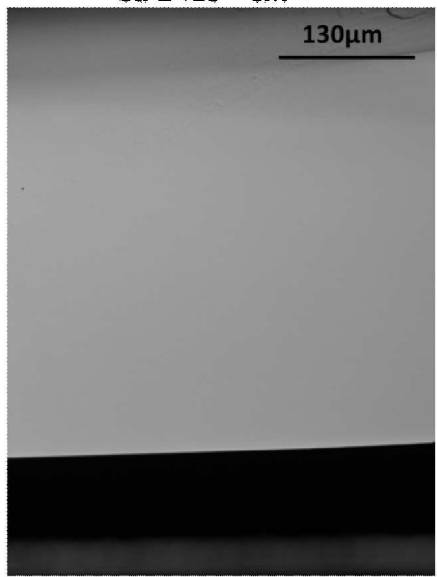

after 7 day storage test Cu $1 \times 10^{12} \mathrm{~cm}^{-2}$

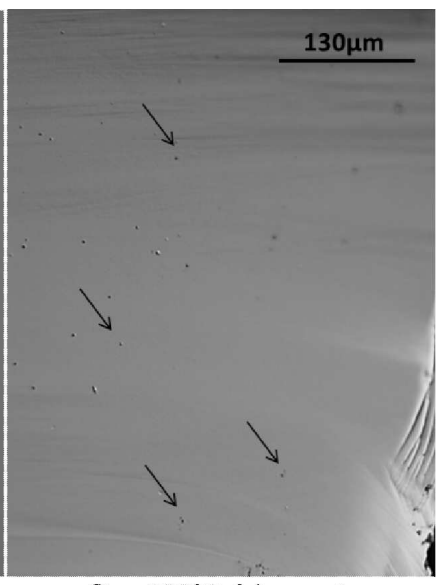

after $400^{\circ} \mathrm{C}$ drive-out

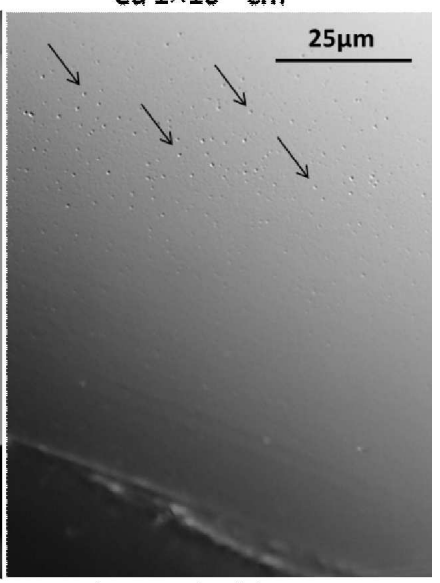

after $250^{\circ} \mathrm{C}$ drive-out Cu $1 \times 10^{12} \mathrm{~cm}^{-2}$ $\mathrm{Cu} 1 \times 10^{12} \mathrm{~cm}^{-2}$

Fig. 4. $\quad \mathrm{CZ}$ as-grown sample subjected to a drive-out anneal or a 7 day storage test etched by the Secco etchant. Arrows indicate some of the etch pits of $\mathrm{Cu}$ precipitates.

precipitates during the drive-out anneal. However, if the sample is stored at RT the $\mathrm{Cu}$ atoms can easily diffuse out. Therefore only the 7 day storage test can be used for the determination of the getter efficiency.

\subsection{Cu getter efficiency}

Now, the 7 day storage test was used for the determination of the getter efficiency. The getter efficiency was calculated according to equation

$$
\eta_{7 \text { day }}=\left(1-\frac{\mathrm{Cu}_{\text {In }}}{\mathrm{Cu}_{\text {Ref }}}\right) 100 \%,
$$

where $\mathrm{Cu}_{\text {In }}$ is the concentration of $\mathrm{Cu}$ measured on the surface of the sample after 7 day storage at $\mathrm{RT}$ and $\mathrm{Cu}_{\mathrm{Ref}}$ is the concentration of $\mathrm{Cu}$ measured on the surface of the sample after the contamination.

Figure 5 shows the $\mathrm{Cu}$ getter efficiency as a function of the BMD density for samples subjected to a growth anneal at $1000{ }^{\circ} \mathrm{C}$ for $16 \mathrm{~h}$. Such samples are characterized by large oxygen precipitates with comparable size 


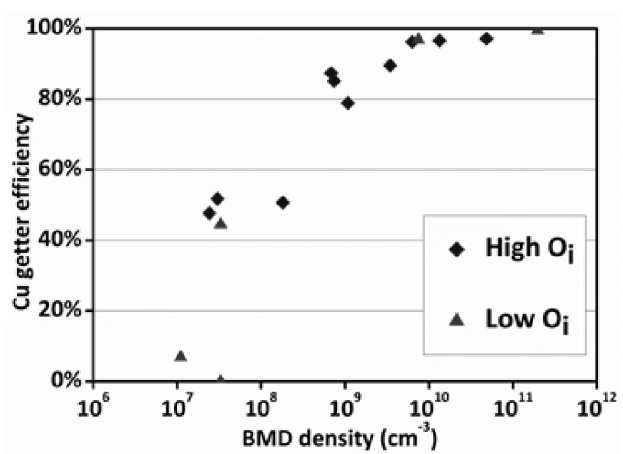

Fig. 5. $\mathrm{Cu}$ getter efficiency as a function of the BMD density for oxygen precipitates of nearly equal size. The initial concentration of $\mathrm{Cu}$ was $\approx 1 \times 10^{13} \mathrm{~cm}^{-2}$.

accompanied by secondary defects like punched-out dislocations and stacking faults. The different density of the defects was achieved by an RTA pre-treatment of the samples at various temperatures which were subsequently annealed at various nucleation temperatures. The getter efficiency increases with an increasing density of defects and saturates for a BMD density of $6 \times 10^{9} \mathrm{~cm}^{-3}$. This value is in a good agreement with the values obtained in Ref. [12] and about one order of magnitude higher than the value obtained by Isomae et al. [4]. The reason why Isomae et al. observed efficient $\mathrm{Cu}$ gettering by a BMD density of $5 \times 10^{8} \mathrm{~cm}^{-3}$ could be that it was a different type of getter test. They contaminated the back surface of the samples and after an in-diffusion step at $1000{ }^{\circ} \mathrm{C}$ for $5 \mathrm{~min}$ by using RTA, they measured the $\mathrm{Cu}$ concentration on the front surface. By comparing the concentration of $\mathrm{Cu}$ on the surface with the referential concentration they determined getter efficiency. The high getter efficiency achieved for a low BMD density could be the results of the $\mathrm{Cu}$ measurement carried out directly after in-diffusion step. As it was observed in this work $\mathrm{Cu}$ needs much more time to diffuse out from the $\mathrm{Si}$ bulk. A high getter efficiency of about $90 \%$ in the samples directly after the drive-in step was always observed but after 7 day storage it decreased far below $90 \%$.

\section{Conclusions}

In this work the development of a 7 day storage getter test was presented. By means of the 7 day getter test, the getter efficiency in the samples contaminated with low concentration of $\mathrm{Cu}$ was determined. The results were compared to the results of other authors. The development of the getter test and the results of the getter test carried out on the samples contaminated with low concentration of $\mathrm{Cu}$ have shown that:
1. The contamination step requires pre-treatment in $\mathrm{HF}(50 \%)$ solution for reliable $\mathrm{Cu}$ concentration measurements by ToF-SIMS.

2. The detection limit of the $\mathrm{Cu}$ concentration measurement by ToF-SIMS on Si substrates equals $1 \times 10^{10} \mathrm{~cm}^{-2}$.

3. Directly after the drive-in step, most of the $\mathrm{Cu}$ remains in the Si bulk.

4. After 7 day storage at RT most of the ungettered $\mathrm{Cu}$ atoms diffuse out of the bulk. After this step it is possible to distinguish the samples with sufficient gettering from samples with insufficient gettering.

5 . $\mathrm{Cu}$ out-diffusion could not be accelerated by out-diffusion anneals at $250{ }^{\circ} \mathrm{C}$ or $400^{\circ} \mathrm{C}$ for $\mathrm{Cu}$ contamination levels of $1 \times 10^{12} \mathrm{~cm}^{-2}$ and $1 \times 10^{13} \mathrm{~cm}^{-2}$ because $\mathrm{Cu}$ precipitates during these anneals.

\section{References}

[1] K. Graff, in: Metal Impurities in Silicon-Device Fabrication, Springer Ser. Mater. Sci., Springer, 1995, p. 24.

[2] R.J. Falster, G.R. Fisher, G. Ferrero, Appl. Phys. Lett. 59, 809 (1991).

[3] M. Seacrist, M. Stinson, J. Libbert, R. Standley, J. Bins, in: Semiconductor Silicon/2002, Eds. H.R. Huff, L. Fabry, S. Kishino, PV 2002-2, The Electrochemical Proceeding Series, Pennington, NJ 2002, p. 638 .

[4] S. Isomae, H. Ishida, T. Itoga, K. Hozawa, J. Electrochem. Soc. 194, G343 (2002).

[5] M.B. Shabani, T. Yoshimi, H. Abe, J. Electrochem. Soc. 143, 2025 (1996).

[6] M.B. Shabani, Y. Shiina, F.G. Kirscht, Y. Shimanuki, Mater. Sci. Eng. B 102, 313 (2003).

[7] R. Hölzl, M. Blietz, L. Fabry, R. Schmolke, Electrochem. Soc. Proc. 2002-2, 608 (2002).

[8] H. Wong, N.W. Cheung, P.K. Chu, J. Liu, J.W. Mayer, Appl. Phys. Lett. 52, 1023 (1988).

[9] Y.M. Guerguiev, R. Kögler, A. Peeva, A. Mücklich, D. Panknin, R.A. Yankov, W. Skorupa, J. Appl. Phys. 88, 5645 (2000).

[10] B.R. Hart, S.S. Dimov, R.St.C. Smart, Surf. Interface Anal. 43, 449 (2011).

[11] K. Hozawa, S. Isomae, J. Yugami, Jpn. J. Appl. Phys. 41, 5887 (2002).

[12] E.R. Weber, Impurity Precipitation, Dissolution, Gettering, and Passivation in PV Silicon, Final Technical Report, February 2002, NREL/SR-520-31528. 